\title{
Nadie es profeta en su propia tierra: santa Teresa de Jesús (1515-1582) en lo imaginario colectivo de su época
}

\section{The Rocky Road to Sainthood: Saint Teresa of Avila (1515-1582) in the Collective Imagination of her Times}

\section{Robin Ann Rice}

Universidad Popular Autónoma del Estado de Puebla (UPAEP)

MÉXICO

niborecir@hotmail.com

[Hipogrifo, (issn: 2328-1308), 4.2, 2016, pp. 43-57]

Recibido: 06-01-2016 / Aceptado: 17-02-2016

DOI: http://dx.doi.org/10.13035/H.2016.04.02.05

Resumen. Santa Teresa de Jesús es el modelo más importante en la actualidad de la religiosidad femenina. Sin embargo, en sus tiempos, tanto sus acciones como su persona estaban bajo el escrutinio escéptico de la jerarquía eclesiástica. Por medio de un análisis de La vida de Santa Teresa de Jesús (1590) de Francisco de Ribera y una de las muchas comedias redactadas para su beatificación en 1614, La bienaventurada madre Santa Teresa de Jesús, obra apócrifa de Luis Vélez de Guevara, propongo configurar un retrato de la santa desde el punto de vista de lo imaginario colectivo de su época. Su configuración en lo imaginario colectivo no era siempre positiva.

Palabras clave. Santa Teresa, hagiografía, comedia de santos, imaginario colectivo.

Abstract. Saint Teresa of Jesus is the most important modern model for feminine religiosity. Nevertheless, in her times, her actions and her persona were under the ecclesiastical hierarchy's skeptical scrutiny. By means of an analysis of La vida de Santa Teresa de Jesus (1590) by Francisco de Ribera and of one of the many comedies composed for her beatification in 1614, La bienaventurada madre Santa Teresa de Jesús, an apocryphal work by Luis Velez de Guevara, I propose to confi- 
gure a portrait of the Saint from the point of view of the epoch's collective imagination. Her configuration in the collective imagination was not always positive.

Keywords. Saint Teresa, Hagiography, Comedy of Saints, Collective Imagination.

Santa Teresa de Jesús es una de las figuras femeninas más importantes de la iglesia católica. Primera doctora de la Iglesia, es celebrada como la fundadora de una orden religiosa presente en todo el mundo y de mucha importancia hasta la fecha. Su preponderancia ha aumentado con el paso de los siglos pese a la gran fama que gozó en sus tiempos. Durante su vida, la fundadora de las Carmelitas Descalzas y los Descalzos tuvo mucho renombre, a veces ambiguo, pero su persona siempre fue provocadora. A 500 años de su nacimiento, tenemos muy clara su relevancia en el desarrollo intelectual, espiritual y místico del ser humano y su nueva relación intersubjetiva con lo Supremo que introdujo al mundo en sus textos. En efecto, el Libro de la vida describió por primera vez los grados de oración, el Camino de perfección, Las moradas, entre otros textos resignificaron la experiencia espiritual y mística del orante del mundo moderno temprano ante Dios. Sin embargo, en el siglo XVI, su fama era confusa, pues, el Libro de la vida estuvo en manos inquisitoriales por trece años y en 1589, siete años después de su muerte, teólogos de la Inquisición exhortaron a quemar sus escritos ${ }^{1}$. En 1588, fray Luis de León editó por primera vez las obras de la santa que ya habían circulado precariamente en forma de manuscritos y en 1590, el jesuita, fray Francisco de Ribera publicó la primera hagiografía de la santa intitulada Vida de Santa Teresa de Jesús. Paulatinamente, en el siglo XVII, hubo un 'enderezamiento doctrinal' de Teresa posiblemente relacionado con el auge de la Compañía de Jesús, grandes defensores y aliados suyos. En 1614 fue beatificada y en 1622, en un tiempo récord, fue canonizada.

El 'enderezamiento doctrinal' se refiere al retrato claroscuro de la Madre que la caracterizaba en su vida. Por un lado, noticias de su vida santa y prodigiosa circularon por toda España y tenía defensores importantes y poderosos. Por el otro lado, hubo detractores que no podían admitir fundaciones tan importantes tanto de monasterios de descalzas como de descalzos por una mujer que llamaron despectivamente 'una beata', 'una mujercilla', 'una doncella', pues ella combinó la vida contemplativa reservada para las mujeres con la vida activa y dinámica, privilegio de los clérigos. Además, había pugnas intestinas entre las diversas órdenes religiosas y la santa, por nunca quedarse apática y quieta, se encontraba, a veces, en medio de estas guerreas. Las circunstancias de su vida que cobraron más fama en la época eran: la manera milagrosa en que solventaba gastos durante la fundación de sus conventos, la polémica de vivir de limosnas versus el de cobrar rentas para el sustento de los conventos, el peligro y la incomodidad que le causaron confesores y guías espirituales ignorantes, las murmuraciones y alborotos que ocasionaron sus fundaciones, y los milagros inofensivos

1. Weber, 1990, p. 35 
relacionados con ella en vida y, después de su muerte, los milagros que aumentaron en cantidad y espectacularidad. El propósito de este estudio es de revisar cómo santa Teresa fue trazada por lo imaginario colectivo durante y después de su muerte. Primero, analizaré la comedia escrita supuestamente para su beatificación en 1614, atribuida a Vélez de Guevara², y la primera vida o hagiografía escrita sobre ella, la Vida de Santa Teresa de Jesús de Francisco de Ribera, de 1590, para poder reconstruir cómo era concebida en su época pues, la vida era una recopilación de noticias conocidísimas sobre la mujer y la materia prima de la comedia proviene de la vida. También, hay escenas en la comedia que contienen información del Libro de la vida, autobiografía de la santa, editada por fray Luis de León en 1688. En todo el mundo las celebraciones por los 500 años del nacimiento de la primera doctora de la Iglesia son una muestra de la gran importancia de santa Teresa para la identidad y la doctrina cristianas, pero en su siglo, no fue así. Teresa tuvo que navegar las aguas turbulentas de la fundación de una orden religiosa importante y de una nueva manera de vivir la espiritualidad.

Santa Teresa era ya célebre entre sus contemporáneos pero aun así su fama creció e información sobre su persona ayudó paulatinamente a difundir la vida portentosa de la santa antes de su beatificación en 1614³. La hagiografía de 1590 es un documento detalladísimo y vasto que relató escrupulosamente su vida religiosa, también, desmenuzó el periodo después de su muerte cuando su cuerpo fue desperdigado y pedacitos fueron extraídos, a veces subrepticiamente, para abastecer reliquias, enviadas a todos lados para inspirar devoción y efectuar milagros. La hagiografía de Ribera contribuyó en gran medida a crear una audiencia europea atenta a las hazañas de la monja gracias a las traducciones que se hicieron de la obra al italiano, francés, alemán, flamenco y al latín, la mayoría, entre 1602 y $1620^{4}$. Hubo eventos culturales muy importantes y populares durante semanas para celebrar tanto su beatificación como su canonización e importantes escritores como Cervantes la elogiaron en verso. Hubo una gran cantidad de obras literarias que se produjeron para el evento, pero una, en particular, atribuida tanto a Lope de Vega como a Vélez de Guevara es parte del objeto de estudio de este trabajo. La obra apócrifa de Lope de Vega, La madre Teresa de Jesús, apareció en la segunda lista del Peregrino en su patria en 1618. Por el otro lado, una, llamada La bienaventurada Madre Santa Teresa de Jesús, atribuida a Vélez de Guevara, se editó por Francisco Martorell en Doce comedias de varios autores publicada en Tortosa en 1638. Se supone que la obra estaba destinada a celebrar la beatificación de Teresa en 16145.

2. Vern. 5

3. Quizás esta 'fama' se aumentó por una representación en Salamanca, en julio de 1606 de una comedia titulada La madre Teresa de Jesús «sin duda» de Lope de Vega (McGrady, 2009, p. 51). Además, en 1606, empezó a circularse La vida de Teresa del obispo de Tarazona, Diego de Yepes.

4. Pons, 1908, p. XVI.

5. Según McGrady, Lope de Vega «anunció en la segunda lista del Peregrino, en 1618» una comedia escrita entre 1604 y 1618 intitulada La madre Teresa de Jesús pero insiste que «él nunca la publicó bajo este título». «En 1638 apareció en "Tortosa" [...] un volumen titulado Doce comedias de varios autores, en el cual figuraba una obra llamada La bienaventurada madre santa Teresa de Jesús atribuida a Luis Vélez de Guevara» pero, realmente, se publicó «por un falsario» en Sevilla y (McGrady, 2009, p. 45). 
Por motivos de ilustración, utilizo el texto atribuido a Vélez de Guevara, probablemente apócrifa, para el estudio de la comedia. La información en la comedia tenía que ser celebradísima por el pueblo para que estimulara los conocimientos de dominio popular sobre la santa y produjera el entretenimiento esperado. Los temas dramáticos vienen en su totalidad de la hagiografía popularísima de Ribera.

La comedia es interesante porque nos ilustra tal vez cuáles habían sido las características y los eventos de la vida de la santa más destacados y reconocibles por los espectadores. La obra comienza con dos hombres, don Ramiro y don Diego, que han mandado cartas de amor a Teresa antes de su entrada en el convento de la Encarnación. Su padre, don Alonso, la ha prometido a don Ramiro pero ella había dado su palabra de casarse con don Diego. De todas maneras, ella dice: «Solo digo, / que ser monja es mi deseo» y asegura que «No hay duda que me poner / que nada, Señor, me espanta» ${ }^{6}$ (p. 223), reminiscente de su reconocida oración («Nada te turbe, / nada te espante, / todo se pasa, / Dios no se muda,»). Don Alonso le contesta con una lista sucinta de todas las hazañas de su vida:

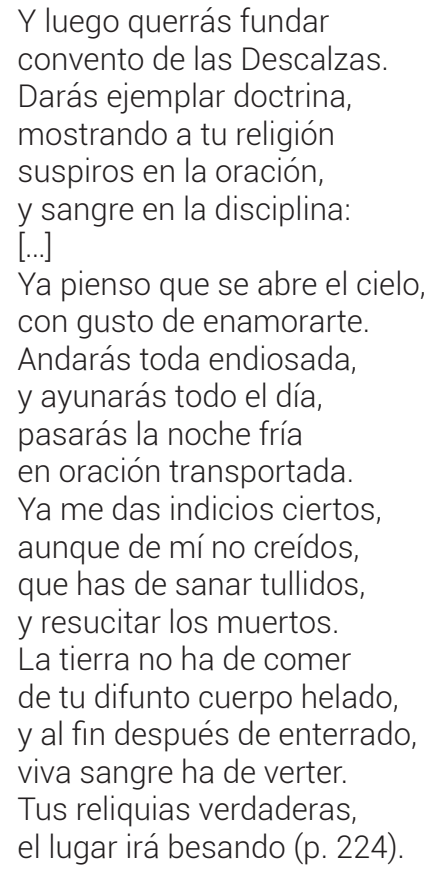

Menciona datos que eran bien conocidos en la época. Su primer hagiógrafo, Francisco de Ribera, relató extensamente las fundaciones de los conventos. Describió las fundaciones como aventuras en que los avances y retrocesos de éstas

Supongo que en 1895 cuando Méndez y Pelayo reimprimió la obra atribuida a Vélez de Guevara como obra de Lope en las Obras (t. V), lo hace en base a que La Barrera «adscribe esta obra sin dudas a Lope» (McGrady, 2009, p. 45).

6. Todas las citas son de Vélez de Guevara, La bienaventurada madre Santa Teresa de Jesús. 
crearon cierta tensión dramática en el texto, efectos literarios perfectamente transferibles a la comedia. La monja empezó casi sola y poco a poco enlistó a un grupo nutrido de seguidores que ella distribuyó en los conventos por toda España.

Como ejemplo del estilo narrativo del padre y del tipo de eventos que incluyó en su texto y que todo el mundo habría sabido de la historia y reconocido con facilidad en la comedia, vemos la fundación del primer convento en Ávila. La idea del primer convento nació de una broma por parte de una sobrina de Teresa que «andaba muy llena de éstas que llaman galas y para andarlo tenía ingenios extraños e invenciones que espantaban» ${ }^{7}$ (pp.152-153). Por las descripciones del hagiógrafo, parece que el convento de la Encarnación, donde Teresa era monja, siempre estaba alborotado, pues, narra el padre que la sobrina, seglar en la Encarnación, estaba en la celda de Teresa con su hermana y con otras parientes y sobrinas de la monja y con una amiga, Juana Suárez. Durante este jolgorio, la sobrina pasó por una transformación milagrosa espontánea porque sugirió, de repente, una vida monástica «más solitaria, a manera de ermitañas» (p. 153) y prosiguió a ofrecer mil ducados para la fundación. Teresa se transformó y aspiró fundar un pequeño monasterio al estilo de las «Descalzas de San Francisco» (p. 154). Empezó a tratarlo con su confesor y con su provincial pero «el demonio [...] levantó una gran borrasca en toda la ciudad, [...] en todos los corrillos se hablaba de ello, y se reían y decían que era disparate y [...] padecían gran persecución» (p. 156). Un padre dominico ayudó a quietar al pueblo y compraron una pequeña casa pero, antes de hacer las escrituras, tuvo que echarse por atrás porque «en el mismo Monasterio de la Encarnación había tantos dichos y tanto alboroto [...] que eran disparates de mujeres [...] [E]n su Monasterio estaba también muy mal quista, [...] y aun algunas decían que la echasen en la cárcel» (pp. 157-158). Por fin, gracias a la intervención de la Compañía de Jesús, se pudo fundar el primer convento en Ávila en 1561. Unos demonios derribaron una pared y tuvieron que pagar, pese a su terrible situación económica, una segunda vez por el trabajo. Este suceso era tan conocido que Vélez de Guevara lo incluyó en su comedia. En la Jornada Segunda, dos demonios, Luzbel y Astarot, planean destruir el convento:

$$
\begin{aligned}
& \text { Astarot, caiga en el suelo } \\
& \text { la casa de esta mujer, } \\
& \text { date prisa que recelo } \\
& \text { que a mi pesar ha de ser } \\
& \text { recamara de su cielo (p. 231). }
\end{aligned}
$$

La comedia glosa minuciosamente las actividades de Teresa, y en cierta parte, recuenta con detalles geográficos, los diecisiete conventos de monjas y los diez de frailes que fundó.

La primera fundación causó tanto disturbio que el pueblo llano sabía de las penurias que había sufrido Teresa en las fundaciones de los otros conventos. Ninguno se fundó sin problemas y murmuraciones. Además de los problemas físicos de la fundación, hay grandes contrariedades administrativas. En la comedia, doña

7. Todas las citas son de Ribera, Vida de Santa Teresa de Jesús. 
Juana, hermana de la santa, comenta los problemas evidenciados en los documentos históricos a la vez:

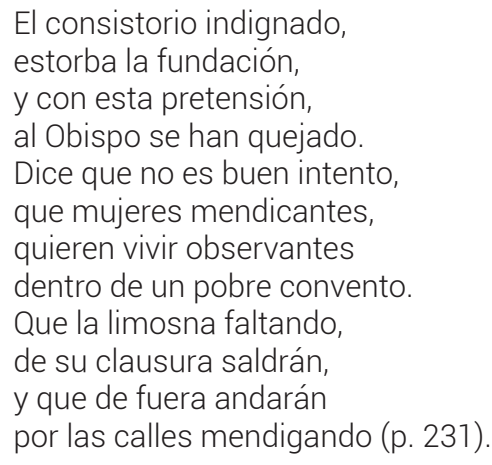

Resume todo el argumento con: «aunque es bien fiar de Dios, / la pobreza es ya sabida, / la casa toda caída, / y la ciudad contra vos» (p. 231). Al inicio de las fundaciones, Teresa anhelaba que «tuviese renta porque viviesen sin cuidado de lo temporal» (p. 190). Después de muchas conversaciones con una beata de su orden, numerosos hombres letrados, sus confesores, y con San Fray Pedro de Alcántara, recientemente muerto, decidió que no habrían de vivir de rentas. Varios años después, cambió de idea y era también el parecer del Concilio de Trento que los monasterios, y especialmente los de mujeres, vivieran de rentas. Teresa quería el sustento de las rentas para poder vivir realmente recogidos pero las jerarquías eclesiásticas se preocupaban más en pensar que las monjas saldrían de sus celdas e interactuarían con la sociedad. Si el asunto ocupó muchos versos en la comedia, también se vio su importancia en la vida por el número de páginas versado sobre él. Uno de los importantes milagros que marcó la Vida y la comedia, como hilo conductor, es la intervención de la Providencia Divina para solventar gastos. La cuestión constante de cómo fueran a pagar el sustento o la fundación de un nuevo convento creaba tensión dramática en la Vida y en la comedia.

Una noticia fundamental en las obras, es la nueva manera de orar que describió la mujer en sus escritos y que cambió radicalmente el concepto de oración en la época moderna temprana pues dio instrucciones para que cualquier persona pudiera acceder o, por lo menos familiarizarse, a una oración profunda anteriormente reservada a los portentos religiosos. En un pasaje de la comedia, su padre hace referencia a los tipos de oración que profesaba Teresa. Supuestamente todos estaban documentados en sus escritos pero Ribera develó que se describieron «por palabras que ella dejó escritas en una relación que hizo fuera de sus libros» ( $p$. 367) supuestamente transmitidos a su confesor y recopilados por primera vez en la hagiografía. La oración teresiana es por escalones o grados que don Alonso describe en la comedia como «suspiros en la oración [...] se abre el cielo, / con gusto de enamorarte. / [...] pasarás la noche fría / en oración transportada» (pp. 223-224).

Teresa los refirió en la relación que dio a su confesor de esta manera. El primer estado es un sencillo percibir la presencia de Dios que conduce al recogimiento 
interior en que los sentidos exteriores están intactos y produce una quietud y un sueño «que llaman de las potencias, que ni están absortas, ni tan suspensas que se pueda llamar arrobamiento, ni es del todo unión» (p. 369). La diferencia es que en la unión «ninguna cosa exterior puede obrar porque el entendimiento está como espantado» (p. 370). En la comedia, don Alonso puntualiza el frío corporal que resulta de la oración que es precisamente la suspensión. La santa constriñó la diferencia entre arrobamiento, suspensión y rapto en estos términos. El arrobamiento y la suspensión son muy parecidos: «no se puede hablar ni los ojos abrir» (p. 370). La suspensión dura más y «la unión [es] con mayor fuerza porque el calor natural se va [...] quedan las manos heladas y algunas veces extendidas como unos palos y [...] y es tanto lo que se emplea en el gozo de lo que el Señor representa que parece que se olvida de animar al cuerpo y [...] quedan los nervios con sentimiento» (p. 370). El rapto se diferencia de la suspensión en que en la suspensión, «va poco a poco muriéndose a estas cosas exteriores y perdiendo los sentidos [y] [e]l rapto viene con una sola noticia que su Majestad da en lo muy íntimo del alma con una velocidad que la parece que la arrebata a lo superior de ella» (pp. 370-371). El vuelo del espíritu y el ímpetu son estados que vienen de la memoria de la oración y que son instantáneos y no son precedidos por la oración consciente. La imagen de santa Teresa más difundida es cuando está en una oración que ella denominó como «herida» que influyó tanto en los versos de don Alonso en la comedia como en la iconografía teresiana, por ejemplo, la escultura de Bernini. La herida es una oración que es «una manera de herida que padece el alma como si una saeta la metiese por el corazón [...] así causa un dolor tan grande que hace quejarse y tan sabroso que nunca querría le faltase» (p. 372). Otras veces, puede parecer como una herida de amor que depende totalmente de Dios y no proviene del ser y su oración, en que el alma desea gozar de Dios pero no logra completamente la unión porque el cuerpo le estorba.

En la comedia, don Alonso describe los sacrificios físicos que haría su hija: «sangre en la disciplina [...] ayunarás todo el día» (pp. 223-224) hechos documentados en la vida que escribió Ribera. Relató su afición de traer cilicios y «tomaba grandes disciplinas de sangre [...] quisiera despedazar su cuerpo [...] usaba disciplinarse con ortigas $^{8}$ hasta venírsele a hacer llagas con materia y tornaba a refrescarlas con tornarla a tomar de las mismas ortigas» (p. 478). Una vez, quebró su propio brazo y luego permitió que unos muy sádicos hueseros lo intentaran resanar pero la cura dolió más que la enfermedad. En su comida era muy parca: «era la comida unas poleadas de harina y un huevo con algunas pocas zanahorias $u$ otra cosilla de legumbres [...] nueces también solía comer y pasas y algún huevo o algún poco de pescado» (p. 479). Un día le llevaron una gallina pero no le pudieron convencer de comérsela.

En la comedia, los dos pretendientes, don Ramiro y don Diego, aparecen en el aposento de Teresa para intentar convencerle de desposarse con uno de ellos y el padre de ella, don Alonso, los sorprendió. La comedia refleja datos verídicos en cuanto a unos coqueteos que Teresa tuvo con un primo suyo, que en la comedia,

8. Ortigas: plantas con dientes muy agudos. 
es Diego. También, hay un escándalo en la comedia relacionado con una prima de Teresa que la descaminó por un tiempo. La santa misma confesó estas desviaciones en el Libro de la vida.

Comencé a traer galas y a desear contentar en parecer bien, con mucho cuidado de manos y cabello y olores, y todas las vanidades que en esto podría tener, que eran hartas por ser muy curiosa. Tenía primos hermanos algunos, que en casa de mi padre no tenían otros cabida para entrar, que era muy recatado; Tenía primeros hermanos algunos [...] [e]ran casi de mi edad, poco mayores que yo; andábamos siempre juntos; [...] tenía una hermana de mucha más edad que yo, de cuya honestidad y bondad, que tenía mucha, de ésta no tomaba nada, y tomé todo el daño de una parienta que trataba mucho en casa (pp. 140-141).

Uno de sus primos hermanos se llamaba Diego, hijo de Elvira de Cepeda9. En la comedia, van a un sarao y Teresa se excusa para ir a la Encarnación para rezar por la ayuda de Dios en escoger un marido. Pide a Dios su consejo y escucha la voz del sacristán hablando con Leonido cuando dice: «con Cristo se puede ir» (p. 225). Teresa piensa equivocadamente que es la voz de Dios dándole a ella la solución a su dilema. Ella interpreta que Dios le dé órdenes de casarse con Jesús y esto es determinante en su decisión. Ribera discutió en la hagiografía las veces en que Dios comunicó muy claramente con Teresa y esta experiencia es reforzada por el padre Francisco de Borja de la Compañía de Jesús. En general, la santa tuvo problemas con sus superiores cuando se trataba del asunto de estas conversaciones porque muchos las llamaban 'embustes'. Otro padre reunió a cinco o seis siervos de Dios que dictaminaron que era el demonio que le hablaba. En su vida, estos coloquios divinos eran origen de mucha ansiedad y el padre Ribera notó «que hubo más de uno que la quiso conjurar como a endemoniada [...] y el ver que algunas veces que los confesores venían con miedo a confesarla y temer que había de venir a tiempo que no hallase quien la quisiera confesar» (p. 134). Por esto, quizás, Vélez de Guevara mofó de la conversación fallida que la carmelita tuvo con Dios en la Encarnación y da por entender que las voces que le hablan son el resultado de una suerte de 'cruce de cables'. En la comedia, don Alonso y los dos pretendientes la siguen al convento y le exigen que tome una decisión y Teresa les contesta: «Y por no dejar celoso / a ninguno de los dos; / nombro por esposo a Dios, / que es verdadero esposo» (p. 226).

En su autobiografía, Libro de la vida, Teresa relató las penurias que sufría por ciertas visiones celestiales que se le presentaron: «Hartas afrentas y trabajos he pasado en decirlo y hartos temores y hartas persecuciones» ${ }^{10}$. Unos confesores que habían creído en la veracidad de la santa, empezaron a dudarla. Por esto, Teresa relató que Gonzalo de Aranda, uno de los guías espirituales «que atormentaban» a la mujer, dijo que cuando viera al Señor, «diese higas, porque tuviese por cierto 
era demonio» ${ }^{11}$. En la comedia Teresa da «higas y cruces» ${ }^{12}$ al Niño Jesús porque su confesor, el padre Mariano, empezó a no creerle:

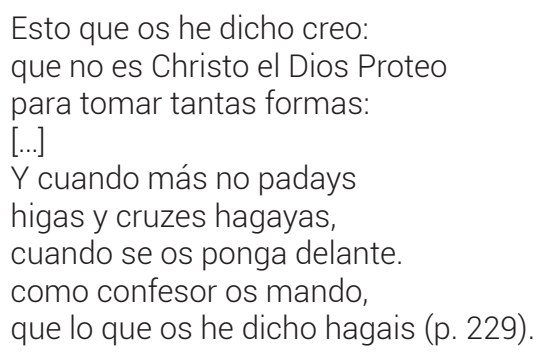

Vélez de Guevara explotó esta frase que en la obra usa una decena de veces para crear un efecto cómico, pues, Teresa no puede distinguir entre visiones celestiales y visiones falsas provocadas por el demonio. Así que tanto a san Pedro como al Niño Jesús, Teresa les da «cruzes con higas, / como el confesor ordena» (p. 230). Unos versos después, Teresa es convencida que sea el Niño Jesús y resignifica la palabra: «Tomad mil higas mi esposo, / que en nadie mi dulce amor / las puede emplear mejor, / que en un Niño tan hermoso» (p. 230). En un acto de reciprocidad, el Niño Jesús regala a Teresa una cruz con bellas piedras, con finos diamantes: «son piedras tan relumbrantes / que me parecen estrellas. / [...]que los diamantes de Dios, / estrellas deben de ser» (p. 230). En la Vida de Santa Teresa, se narró que cuando Teresa estuvo planeando su primer monasterio «andaba en este tiempo pensando a quién sería bueno dar la obediencia después de hecho el monasterio» (p. 164). Tuvo un arrobamiento con la aparición de la Virgen María y San José y le dieron un collar de oro «muy más hermoso que en la tierra se puede hallar, con una cruz de mucho valor que colgaba de él» (p. 165). Esta escena de la imposición del collar por la Virgen María y san José dio lugar a mucho material pictórico en la época y posteriormente.

La comedia incluye milagros famosísimos que están cuidadosamente documentados en la Vida. En uno, Vélez de Guevara cambió el evento pero los resultados son iguales. En la comedia, Teresa corta su dedo y su cuñado, Juan del Valle, le limpia la herida con un lienzo:

$$
\begin{array}{ll}
\text { VALLE } & \text { Yo tengo lienzo, dadme vuestra mano. } \\
\text { TERESA } & \text { No le manchéis, que es lástima ensuciarlo. } \\
\text { VALLE } & \text { El lienzo gana, yo en romperlo gano. } \\
\text { TERESA } & \text { ¿Qué hacéis, señor? }
\end{array}
$$




VALLE Que puedo hacer y rasgarlo:
con el medio ataré la abierta herida,
y el medio por reliquia he de guardarlo (p. 235).

Más adelante, en una disputa, don Diego dispara a don Juan del Valle y el lienzo ensangrentado que guardó en su camisa le protege contra la bala.

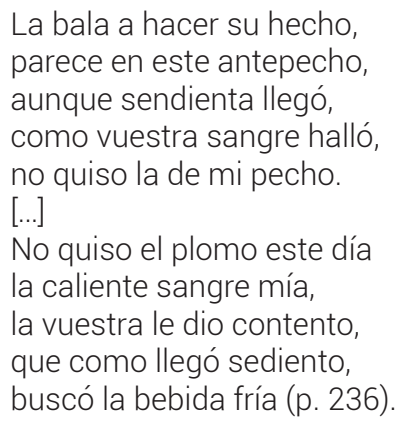

Este milagro no está documentado así en la Vida. Quizás se refiere a un milagro que documentó Ribera en la larga lista de milagros que hicieron las reliquias de la santa después de muerta. Ribera reportó:

Un padre de los Descalzos Carmelitas fue a Alba y tomando el brazo de la Madre [el brazo cortado de su cuerpo como reliquia] en la mano y besándole, cortó con los dientes un poquito como una telita muy seca que estaba levantada y púsolo en un papel; y mirándole a cabo de ocho días, halló en ello una gota de sangre muy viva que había pasado tres dobleces del papel. Y espantado mucho de aqueIlo, quitó aquel papel y puso otro y salió otra gota de sangre (p. 548).

Estos pañitos de sangre eran usados para curar a personas: remedió el oído de una señora principal de Alba, transformó la melancolía de una monja descalza de Alba, quitó los cólicos mortales a Juan de Medina y resucitó de muerte a un niño de dos años, entre otros actos portentosos (p. 549).

Gracias al milagro del lienzo, Diego decide convertirse en fraile: «Pues tan encendido estoy, / que propongo desde hoy / ser fraile» (p. 236). Así que Teresa propone fundar el primer convento de Descalzos en Maqueda:

$$
\begin{aligned}
& \text { Con el rector fray Mariano, } \\
& \text { don Diego, os avaís de ver. } \\
& \text { En Maqueda primo está, } \\
& \text { que es el convento primero } \\
& \text { de mis Descalzos (p. 236). }
\end{aligned}
$$

Maqueda tuvo una vida conventual efímera, entre 1587-1591 y hubo únicamente siete profesiones, todos coristas ${ }^{13}$. 
Después de la mención de la gran maravilla de la santa de fundar los Descalzos, la comedia incluye un milagro que el padre Ribera también documentó. En la obra de Vélez de Guevara, arriban Teresa y Juan del Valle, a la casa de la hermana de la santa. Su sobrino, Gonzalo, hijito de Juan del Valle y doña Juana, hermana de la santa, ha muerto. Todos están aliviados cuando llegue Teresa y a la espera de que la carmelita lo resucite. Teresa pide a Dios que lo reviva y pide al niño: «¿No me habláis, niño querido?» (p. 237). El niño empieza a hablar pero regaña a su tía Teresa por haberle privado de la compañía de Dios. En la Vida de Ribera, sucedieron los mismos hechos y reviró el autor: "De esto hay hoy testigos de vista, algunos bien dignos de fe que me lo han contados mí» (p. 166).

Regresó Teresa a Alba y empezó a morir con la ayuda del Amor Divino que es su Cirineo. Cuando muere Teresa en la comedia, suceden una serie de milagros que el padre Ribera documentó también en la Vida.

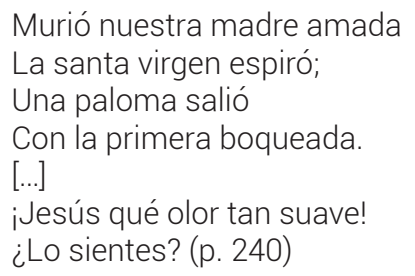

En la Vida de Ribera, sucedieron los mismos milagros:

Quedó su rostro hermosísimo, como murió, y sin arruga ninguna, aunque solía tener hartas; todo el cuerpo muy blanco y también sin arrugas, que parecía alabastro; la carne tan blanda y tan tratable como la suelen tener los niños de dos o tres años. [...] De todo el cuerpo salió un olor muy suave, que nadie pudiera decir a qué olor se parecía, y de rato a rato venía más suave, y era tan fuerte, que hubieron menester abrir la ventana, porque dolía la cabeza a las que estaban. [...] pasaba aún mucho olor, y por toda la casa andaba aquella noche, y el día siguiente, y quedó entonces este olor en sus vestidos y ropa (p. 339).

El olor siguió difundiéndose y por fin, llegó a toda la casa y se volvió un olor imborrable en cualquier cosa que le hubiera tocado. Otra característica que marcó la muerte de la Santa en toda la literatura sobre su persona, es la paloma que salió de su boca: «Y al tiempo que expiraba, vio una hermana una como palomita blanca que salía de la boca. [...] Y en expirando, vio otra hermana una gran luz cristalina junto a la ventana de la misma celda» (pp. 341-342).

Santa Teresa dejó muchos escritos pero tenía cuidado de no extralimitarse. El Libro de la vida era una especie de apología y midió sus palabras para no causar más sospechas sobre su persona. En la Vida de Ribera, vemos los problemas que ya tuvo por las murmuraciones, las difamaciones, los alborotos, etc. No pudo arriesgarse de tener más problemas con escritos que levantarían sospechas. Por esto, una comprensión acertada de la mujer se obtiene por medio de sus escritos pero, también, por los de su época. La monja empezó a causar ruido donde fuera. Tenía aliados muy importantes y de mucha alcurnia que la pudieran alejar del peligro. 
En una época milagrera, la fama de Teresa aumentó mucho después de su muerte por todos los milagros reportados por personas que usaron sus reliquias para curaciones. Su brazo izquierdo, manco desde cuando los demonios la derribaron, fue enviado a Lisboa, su brazo derecho se quedó en Alba, y el resto de su cuerpo se trasladó a Ávila pero por los enfados que causó el cambio, regresaron el cuerpo a Alba. Otra vez en Alba, mostraron el cuerpo al público pero «fue bien menester, estar detrás de reja, porque según era la muchedumbre y devoción e ímpetu de la gente, si estuviera fuera, hicieran pedazos el hábito, para tomar reliquias, y aun el cuerpo corriera peligro» (p. 533). Al inicio, hubo muchas apariciones de la Madre Teresa, después, Ribera relató con detalle los milagros que hizo Teresa y los dividió por tipo. Los primeros son los «que se han hecho con cosas de su cuerpo, como con el mismo cuerpo, o la mano, o la sangre. En el segundo, los que se han hecho con reliquias de sus vestidos. En tercero los que se han hecho con su imagen. En el cuarto los que se han hecho por encomendarse a ella» (p. 545) y son cientos de estos milagros.

Los milagros ayudaron mucho en propagar la fama de Teresa. Ejemplos de los milagros que hicieron con reliquias de su cuerpo son muchos: con diferentes partes del cuerpo, curaron los oídos de un fraile, los ojos semiciegos de un carpintero, los pensamientos asesinos de un caballero que quería matar a su esposa. En un caso muy sonado, salvó de muerte al hijo del licenciado Vallejo, oidor del Consejo del duque de Alba y subrayó Ribera que había muchos testigos. Parece que los pañitos de sangre circularon bastante porque muchas personas se sanaron con ellos de dolores en los pies, de corazón y de cabeza.

Los milagros con partes del cuerpo de la santa, prendas de ropa y las imágenes volaron a todas partes de España para aumentar su fama en todos los territorios españoles y portugueses. Es notable que hubiera una especie de red que llevaba estos artículos a muchos lugares que atribuyó a la creación de la identidad milagrera de la santa. Si las reliquias de las partes de su cuerpo estaban limitadas a curar personas que vivían cerca de Alba, Ávila y Lisboa, los paños de sangre, los pedazos de su ropa y sus imágenes podían proliferarse más. Por esto, hay noticias desde Peñaranda, Manaria, Durango, Vizcaya, Piedrahita, Navas, Cayo, y Naharros, entre otras latitudes, de curaciones con reliquias más transportables. Las enfermedades más comunes entre el pueblo que requerían de los milagros eran: gran dolor de pecho o zaratán, o cáncer de mama, dolores de dientes, problemas de hígado y flemas saladas que quemaban la boca, mal de ojos y de pintas, tullimiento causado de gota ciática, y postemas por todas partes del cuerpo.

Desde la polémica de sus primeras fundaciones hasta el inicio del proceso de su beatificación y canonización, Teresa tuvo el gran apoyo de la Compañía de Jesús. En 1591, el obispo de Salamanca, Jerónimo Manrique, inició la investigación sobre la incorrupción del cuerpo de Teresa y un testimonio de «la vida, costumbres y milagros» (p. 569) de la Madre con testimonio «de las personas más eminentes en virtud y letras de toda España por ser la mayor parte de ellas maestros de la Universidad de Salamanca» (p. 570). Ya reunidas las 16 informaciones para el compulsorial (proceso canónico) de personas graves, en 1604, mandaron «las informaciones in genere, acerca de la fama de santidad y milagros» (p. 570) de la mujer. En 1607, el 
Papa Paulo V exigió «las informaciones in specie sobre las virtudes y milagros» ( $p$. 571 ) de Teresa. Más de 500 testigos aparecieron en el proceso, llamado remisorial, que documentó toda la información in genere e in specie, y después de mucha ponderación y 32 años desde su muerte y 23 años desde cuando habían empezado con los pasos para la beatificación, la Madre Teresa se beatificó el 24 de abril de 1614. Durante ocho días, hubo celebraciones por todo el Imperio Español. En Madrid, «Regocijaron mucho aquella noche los árboles, bombas y fuentes de fuego, que había galeras, sierpes, ruedas y otras invenciones [...] que con gran ruido que las campanas de tantos monasterios y parroquias hacían y la copia de gente que concurría de todas partes fue en extremo regocijada y solemne» ${ }^{14}$. Hubo certámenes de epigramas, poesías, himnos, himnos extravagantes, canciones, romances, sonetos y una gran participación por parte de Lope de Vega entre otros. Hubo fiestas singulares y lujosas en Barcelona, Burgos, Córdova, Ciudad Real, Granada, Lisboa, Pamplona, Segovia, Valladolid y en más de 80 otras ciudades en España y Portugal. En muchas de las localidades, hubo milagros y sucesos extraños durante los días de las celebraciones $^{15}$. Tanto importantes personajes eclesiásticos como aristocráticos de la tala del Emperador Fernando II, los Reyes de España, Francia y Polonia, el Archiduque de Bélgica, el Duque de Baviera, instaron a Gregorio XV que la canonizaran. Y, por fin, el 12 de marzo de 1622, a la vez de inscribir la Madre Teresa en el catálogo de santas vírgenes, se «decretaron los honores de la Santidad para los Beatos Isidro Labrador, Ignacio de Loyola, Francisco Javier y Felipe Neri» (pp. 571-572).

El 16 de noviembre de 1617, nombraron a Teresa Patrona de España juntamente con el Apóstol Santiago. Para algunos, Teresa era más relevante y la fama de sus actos portentosos era tan extendida que aún había testigos vivos de ellos. En el caso de Santiago, las circunstancias relacionadas con su estado milagroso eran lejanas, del pasado remoto ${ }^{16}$. Pero, lo sagrado tuvo un papel muy importante en el desarrollo y la argumentación de un concepto de 'nación' en este periodo. Además, la cohesión ideológica que aportó Santiago al concepto de una España histórica, pre Habsburgo, era clave ${ }^{17}$. En un breve, el papa Urbano VIII declaró el patronato de Teresa en España. Pero, el debate se convirtió en uno con implicaciones legales complicadas sobre el concepto de nación que involucró las delimitaciones de España. En otras palabras, ¿'España' significaba Castilla o Aragón, Navarra y Portugal también? Asimismo, hubo publicaciones de documentos: Quevedo tomó un papel importante que se vio en 1628 en forma de Memorial por el patronato de Santiago, firmado por él ${ }^{18}$ que algunos definen de tono beligerante en contra de la santa. Inmediatamente, seguidores de Santiago empezaron a protestar y por años hubo serios conflictos que eventualmente causó la publicación en 1629 de la revocación del copatronazgo. Varios catedrales, adheridos al patronazgo único de Santiago,

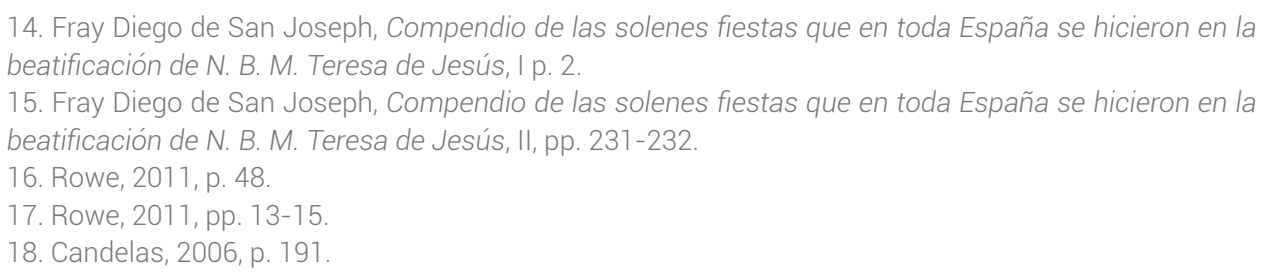


celebraron la decisión. Decretaron la destrucción de todo material impreso con la insignia que representaba Teresa como copatrona y cualquier otra imagen como escudos, epitafios y oraciones que la nombraron como copatrona ${ }^{19}$.

En su época, santa Teresa era conocida y admirada tanto por personas de poder como por el pueblo llano. La literatura imaginativa, como la comedia, retrató a la Madre según los datos asentados por sus hagiógrafos. Su fama era grande y según los testimonios, hubo tantos detractores como admiradores en sus tiempos. Por un lado, la lucha entre órdenes religiosas peligraba con entorpecer el inicio de las fundaciones carmelitas, ser una mujer y necesitar viajar y hacer negocios para adquirir y habilitar los monasterios, y la línea delgada entre la charlatanería y el misticismo agitaron las aguas profundas que la Madre tenía que navegar. Después de 500 años, el mapa en relieve de su vida acentúa los logros, los aciertos y el legado teresianos como si fuera siempre un camino liso e iluminado. Por medio de la comedia y las hagiografías, podemos percibir las dificultades de ser profeta en su propia tierra.

\section{BIBLIOGRAFÍA}

Candelas, Manuel, «Los escritos de Balboa de Morgovejo y Fray Pedro de la Madre de Dios en Su espada por Santiago de Quevedo», en Nueva Revista de Filología Hispánica, 49, 1, 2006, pp. 191-207.

Chicharro, Dámaso, «Introducción», en Libro de la vida, ed. Dámaso Chicharro, Madrid, Cátedra, 2014, pp. 21-130.

Fray Diego de San Joseph, Compendio de las solenes fiestas que en toda España se hicieron en la beatificación de N. B. M. Teresa de Jesús, part. 1-2, Madrid, por la Viuda de Alonso Marín, 1615.

McGrady, Donald, «La autenticidad de dos comedias sobre santa Teresa atribuidas a Lope», Criticón, 106, 2009, pp. 45-55.

Pons, Jaime, «Introducción», en Vida de Santa Teresa de Jesús, ed. Jaime Pons, Barcelona, Gustavo Gili, 1908, pp. V-XXXII.

Ribera, Francisco de, Vida de Santa Teresa de Jesús, ed. Jaime Pons, Barcelona, Gustavo Gili, 1908.

Rowe, Erin, Saint and Nation. Santiago, Teresa de Avila, and Plural Identities in Early Modern Spain, Pennsylvania, Pennsylvania State University Press, 2011.

Satorre, José, «Un nuevo ejemplo de la expresión dar higas», Revista de Filología Española, 72, 1-2, 1992, pp. 177-178.

Teresa de Jesús, santa, Libro de la vida, ed. Dámaso Chicharro, Madrid, Cátedra, 2014. 
Vélez de Guevara, Luis, La bienaventurada madre Santa Teresa de Jesús, en Doce comedias de varios autores, Tortosa, Francisco Murtorell, 1638.

Vizuete, Carlos, «Onomástica y devociones entre los primeros carmelitas descalzos», en El culto a los santos: cofradías, devoción, fiestas y arte, Instituto Escurialense de Investigaciones Históricas y Artísticas. Simposium, Ediciones Escurialenses, Real Centro Universitario Escorial-María Cristina, pp. 91-108.

Weber, Alison, Teresa de Avila and the Rhetoric of Femininity, Princeton, Princeton University, 1990. 
